\title{
PENGUASAAN KONSEP SISWA DALAM PENDEKATAN INTERACTIVE CONCEPTUAL INSTRUCTION (ICI) DENGAN VIDEO PEMBELAJARAN
}

\author{
Dewi Astuti \\ Universitas Sebelas Maret, Surakarta, \\ Indonesia \\ dewi.astuti.170696@student.uns.ac.id
}

\author{
Muna Fauziah \\ Institut Agama Islam Nahdlatul Ulama \\ Kebumen, Indonesia \\ fauziah@iainu-kebumen.ac.id
}

\begin{abstract}
ABSTRAK
Penelitian ini bertujuan untuk menganalisis penguasaan konsep pembelajaran tematik pada pendekatan Interactive Conceptual Instruction dengan video pembelajaran. Sampel dalam penelitian ini adalah 119 siswa kelas IV di empat Sekolah Dasar Negeri di Kecamatan Laweyan, Surakarta, Indonesia. Formulir pre-test dan post-test digunakan sebagai ukuran penguasaan konsep siswa. Instrumen tes yang digunakan adalah tes penguasaan konsep. Hasil pengujian dianalisis secara kualitatif dan kuantitatif. Hasil analisis menunjukkan bahwa pembelajaran berpengaruh terhadap penguasaan konsep dengan kategori sangat kuat. Hasil peningkatan penguasaan konsep oleh siswa sebelum dan sesudah pembelajaran berada pada kategori rendah.
\end{abstract}

Kata Kunci: Pendekatan, interactive conceptual instruction, penguasaan konsep, video pembelajaran

\section{PENDAHULUAN}

Pembelajaran tematik adalah kegiatan pembelajaran yang mengarahkan siswa untuk mengembangkan pengetahuan dengan mengintegrasikan materi pada beberapa mata pelajaran dalam satu tema atau topik bahasan. Pembelajaran tematik dilakukan sebagai upaya pemulihan dan peningkatan mutu pendidikan, terutama untuk mengimbangi ketatnya materi kurikulum. Pembelajaran tematik memberikan kesempatan belajar terpadu yang lebih menekankan pada partisipasi atau keterlibatan siswa dalam pembelajaran. Pembelajaran ini berpusat pada anak, di mana pengalaman, minat, dan kehidupan dunia anak merupakan fondasi penting bagi keterlibatan dan proses belajar 
anak. ${ }^{1}$ Proses dalam pembelajaran tematik membutuhkan metode pengajaran yang mengandalkan umpan balik dan penguasaan sebagian topik sebelum pindah ke bagian berikutnya. $^{2}$

Salah satu indikator keberhasilan belajar memiliki penguasaan yang baik. Penguasaan konsep merupakan salah satu tujuan utama pembelajaran. ${ }^{3}$ Penguasaan konsep adalah kemampuan memahami konsep secara teoritis dan menerapkan konsep tersebut untuk memecahkan suatu masalah. ${ }^{4}$ Penguasaan konsep di Indonesia digunakan untuk mengukur sejauh mana keberhasilan guru dengan menggunakan pendekatan pembelajaran, media pembelajaran, dan pemberian umpan balik. Tingkat penguasaan konsep siswa pada umumnya dikaitkan dengan kegiatan pembelajaran yang menuntut siswa untuk mengkonstruksi pengetahuannya secara aktif. Kenyataan di lapangan sering dijumpai adanya kesulitan pada sejumlah siswa dalam memahami beberapa konsep. Aspek penguasaan konsep siswa sesuai dengan tingkat proses kognitif yaitu mengingat, memahami, menerapkan, menganalisis, mengevaluasi, dan mencipta. ${ }^{5}$

Sejumlah hasil penelitian menunjukkan bahwa beberapa siswa mengalami kesulitan dalam memahami sejumlah konsep dengan rata-rata yang rendah. ${ }^{6}$ Penguasaan konsep dari siswa yang berbeda diperoleh melalui studi percontohan. ${ }^{7}$ Ditemukan fakta empiris dari lapangan di Sekolah Dasar Negeri (SD) Begalon II, Surakarta, Indonesia pada tanggal 29 Juli 2019 menunjukkan bahwa sebanyak 31 dari 40 mendapat nilai di bawah minimum (Kriteria Ketuntasan Minimum = 70), dengan perolehan rata-rata 66. Berdasarkan kegiatan wawancara dengan enam siswa, mereka kurang memahami materi

${ }^{1}$ Robin Samuelsson, "Learning, culture and social interaction children's explorations of the concept of spinning in preschool: Science learning in mediated activity", Learning, Culture and Social Interaction, Vol. 1, 2018, pp. 1-13. https://doi.org/10.1016/j.lcsi.2018.01.002.

2 Nicolas Thibodeau-Jarry, Daniel Bamira, \& Michael Picard, "Spotlight on special topics using simulation to teach transthoracic echocardiography to cardiology", Journal of the American College of Cardiology, Vol. 71, No. 11, 2018, pp. A2655. https://doi.org/10.1016/S07351097(18)33196-6.

${ }^{3}$ Anne T. Estapa \& Kristina M. Tank, "Supporting integrated STEM in the elementary classroom: a professional development approach centered on an engineering design challenge", International Journal of STEM education, Vol. 4, No. 1, 2017, pp. 1-16.

${ }^{4}$ Szu-Chun Fan \& Kuang-Chao Yu, "How an integrative STEM curriculum can benefit students in engineering design practices", International Journal of Technology and Design Education, Vol. 27, No. 1, 2017, pp. 107-129. https://doi.org/10.1007/s10798-015-9328-x

5 Lorin W. Anderson \& David R. Krathwohl, D.R. (Ed, Kerangka landasan untuk pembelajaran, pengajaran, dan asesmen, (Yogyakarta: Pustaka Pelajar, 2010).

${ }^{6}$ Wa Ode Lidya Arisanti, Wahyu Sopandi, \& Ari Widodo, "Analisis penguasaan konsep dan keterampilan berpikir kreatif siswa SD melalui project based learning", EduHumaniora, Vol. 8, No. 1, 2016, hlm. 82-95.

7 Ela Suryani, Ani Rusilowati, and Wardono, "Analisis pemahaman konsep IPA siswa SD menggunakan two-tier test melalui pembelajaran konflik kognitif", Jurnal Prima Edukasi, Vol. 5, No. 1, 2016, hlm 56-65. 
yang disampaikan guru, apalagi materinya abstrak dan sulit dibayangkan siswa, karena pembelajaran yang dilakukan lebih terfokus pada hasil. Siswa hanya menghafal teori tanpa mendalami proses atau peristiwa yang terjadi, sehingga materi yang disampaikan sulit diingat siswa dalam jangka waktu yang lama. Materi pelajaran yang diberikan hanya sebatas cakupan materi yang ada pada buku tematik, sehingga cakupan materinya kurang luas untuk menghadapi tantangan masa depan yang semakin rumit dan kompleks.

Maka, tidak heran jika hasil Trend International Mathematics and Science Study (TIMSS) dan PISA tahun 2007-2012 menunjukkan bahwa penguasaan konsep IPA yang dimiliki siswa Indonesia masih rendah. Beberapa penelitian telah dilakukan untuk mengatasi rendahnya penguasaan konsep siswa diantaranya Erol \& $\mathrm{Kurt}^{8}$; Castro et al. ${ }^{9}$; Vidermanova ${ }^{10}$ upaya untuk mengatasi kesulitan penguasaan konsep siswa dengan menerapkan pendekatan pembelajaran dan penggunaan media pembelajaran.

Masalah seperti itu membutuhkan tindakan pencegahan segera. Banyak hal yang mungkin terjadi jika dibiarkan begitu saja. Faktor yang mempengaruhi penguasaan materi berupa waktu yang dihabiskan dan waktu yang dibutuhkan. ${ }^{11}$ Setiap anak memiliki waktu yang dibutuhkan untuk belajar pada beberapa tingkat kriteria, dan jika anak menghabiskan waktu yang tepat, mereka akan menguasai lebih banyak konsep. Namun jika waktu yang tersedia tidak cukup atau anak tidak menghabiskan waktu yang dibutuhkan, maka tingkat penguasaan konsep anak dalam pembelajaran jauh lebih sedikit dan tidak akan tuntas. Dengan kata lain, waktu yang dihabiskan ditentukan oleh ketekunan anak pada tugas belajar dan jumlah waktu belajar yang disediakan. Waktu yang dibutuhkan berkaitan dengan tingkat pembelajaran anak dan kualitas serta kemampuan untuk memahami instruksi.

Berbagai upaya dilakukan dengan menerapkan strategi khusus untuk meningkatkan

${ }^{8}$ Osman Erol \& Adile Aşkım Kurt, "The effects of teaching programming with Scratch on preservice information technology teachers' motivation and achievement", Computers in Human Behavior, Vol. 77, 2017, pp. 11-18.

9 Alison Castro Superfine, Julie Amador, and John Bragelman. "Facilitating video-based discussions to support prospective teacher noticing", The Journal of Mathematical Behavior, Vol. 54, 2019, pp. 100681.

${ }^{10}$ Kitti Vidermanova, and Dusan Vallo. "Practical geometry tasks as a method for teaching active learning in geometry", Procedia-Social and Behavioral Sciences, Vol. 191, 2015, pp. 17961800. https://doi.org/10.1016/j.sbspro.2015.04.421.

${ }_{11}$ Johnson M. Changeiywo, P. W. Wambugu, and S. W. Wachanga, "Investigations of students' motivation toward learning secondary school physics through mastery learning approach", International Journal of Science and Mathematics Education, Vol. 9, No, 6, 2011, pp. 1333-1350. 
kemampuan dan keberhasilan pembelajaran. ${ }^{12}$ Pendekatan pembelajaran yang paling efektif adalah dengan melibatkan siswa dalam mengembangkan proyeknya daripada langsung menerima pengetahuan yang hanya dijelaskan oleh guru. ${ }^{13}$ Salah satu pendekatan pembelajaran yang dirancang dengan fokus pada penguasaan konsep yang baik di kalangan siswa adalah pembelajaran Interactive Conceptual Instruction (ICI). Pendekatan pembelajaran interaktif konseptual (Interactive Conceptual Instructions) memiliki empat karakteristik: fokus konseptual, interaksi kelas, bahan berbasis penelitian, dan penggunaan teks. ${ }^{14}$

Dalam pendekatan ini, konsep dilakukan oleh guru dan siswa melalui demonstrasi yang berkaitan dengan materi yang akan dipelajari. Penggunaan media pembelajaran berupa video dalam penggunaan tahap teks dapat memperjelas penyajian gagasan dalam menyimpulkan suatu konsep pembelajaran. Kegiatan demonstrasi membentuk arena di mana siswa dapat mengalami pentingnya dan makna penyelidikan. Siswa harus dibekali dengan kemampuan berpikir yang cukup untuk menjawab pertanyaan. ${ }^{15}$ Pengalaman dan pembelajaran dalam proses kegiatan ilmiah dapat membuka jalan untuk mengeksplorasi suatu konsep.

Penggunaan media pembelajaran berupa video adalah sebagai sarana untuk mempertajam penjelasan kegiatan demonstrasi dan menggantikan peran alat peraga terutama yang tidak mungkin dilakukan secara jelas di depan kelas, baik karena peralatan sulit untuk dibangun, atau karena mahal dan langka. Salah satu kelebihan media video adalah siswa tidak hanya mendengar, tetapi juga melihat. ${ }^{16}$ Media video memberikan lebih banyak waktu bagi siswa untuk merespon dan merefleksikan apa yang mereka baca atau amati dan juga memberikan pandangan yang lebih sempit tentang interaksi kelas, dan

12 Chun-Yen Tsai, 'Improving students' understanding of basic programming concepts through visual programming language: The role of self-efficacy", Computers in Human Behavior, Vol. 95, 2018, pp. 224-232. https://doi.org/10.1016/j.chb.2018.11.038.

${ }^{13}$ Osman Erol, \& Adile Aşkım Kurt, "The effects of teaching programming with Scratch on pre-service information technology teachers' motivation and achievement", Computers in Human Behavior, Vol. 77, 2017, pp. 11-18.

${ }^{14}$ Antti Savinainen, \& Philip Scott "Using the force concept inventory to monitor student learning and to plan teaching", Physics Education, Vol. 37, No. 1, 2002, pp. 53-58. https://doi.org/10.1088/0031-9120/37/1/307.

${ }^{15}$ Sherry A. Southerland, Julie Gess-Newsome, \& Adam Johnston "Portraying science in the classroom: The manifestation of scientists' beliefs in classroom practice". Journal of Research in Science Teachıng, Vol. 40, No. 7, 2003, pp. 669-691.

${ }^{16}$ Ghasem Barani, Omid Mazandarani, \& Seyyed Hassan Seyyed Rezaie "The effect of application of picture into picture audio- visual aids on vocabulary learning of young Iranian ELF learners", Procedia - Social and Behavioral Sciences, Vol. 2, No. 2, 2010, pp. 5362-5369. https://doi.org/10.1016/j.sbspro.2010.03.874. 
dengan demikian, penyelidikan lebih fokus pada pemikiran anak-anak.

Media video juga menyediakan informasi yang mewakili situasi nyata dan memilih informasi yang mereka alami secara langsung. ${ }^{17}$ Pembelajaran dengan media video memiliki nilai visualisasi yang lebih tinggi dibandingkan dengan media gambar. Penggunaan fasilitas mobile mendukung guru untuk membuat koneksi dengan prinsipprinsip pembelajaran yang lebih luas dan penekanan pada pengetahuan kognitif. ${ }^{18}$ Media video pembelajaran dapat mempersiapkan siswa untuk mengakses pengetahuan mereka, mengelola interaksi interpersonal mereka, dan meningkatkan potensi untuk membangun pengetahuan mereka.

Perbedaan dalam penelitian ini adalah penggunaan pendekatan media pembelajaran. Davrajoo dkk. mengungkapkan bahwa konstruksi dan penguasaan konsep aljabar membantu siswa menuju sikap positif dalam belajar matematika. ${ }^{19}$ Perbedaan media yang digunakan berupa modul dengan menggunakan pendekatan Mastery Learning, sedangkan dalam penelitian ini menggunakan pendekatan Interactive Conceptual Instruction (ICI) dengan media video. Teks perubahan konseptual lebih efektif dalam menghilangkan konsepsi alternatif siswa dari metode pengajaran tradisional. Perbedaannya adalah penggunaan metode pembelajaran tradisional, sedangkan penelitian ini menggunakan pendekatan ICI dengan media video. Kebaruan dalam penelitian ini adalah menggunakan pendekatan ICI yang terintegrasi dengan media video yang dapat meningkatkan penguasaan konsep.

Berdasarkan uraian di atas, maka diperlukan suatu cara untuk mengatasi permasalahan dalam pembelajaran yaitu dengan menerapkan media pembelajaran yang diimplementasikan dalam suatu pendekatan pembelajaran. Media dan pendekatan pembelajaran tersebut merangsang aktivitas, pikiran, perasaan, dan kehendak setiap siswa sehingga dapat mendorong terciptanya proses belajar dalam diri siswa, yang nantinya akan mempengaruhi penguasaan konsep. Berdasarkan keunggulan pembelajaran ICI, akan dianalisis bagaimana penguasaan konsep siswa sebelum dan sesudah menggunakan pembelajaran ICI dengan media pembelajaran dan kemampuan apa saja dari aspek

${ }^{17}$ Georgene L. Troseth, "Is it life or is it Memorex? Video as a representation of reality", Developmental Review, Vol. 30, 2010, pp. 155-175. http://dx.doi.org/10.1016/j.dr.2010.03.007.

${ }^{18}$ Miray Tekkumru-Kisa, \& Mary Kay Stein "A framework for planning and facilitating videobased professional development", International Journal of STEM Education, Vol. 4, No. 1, 2017, pp. 1-18. https://doi.org/10.1186/s40594-017-0086-z.

${ }_{19}$ Elenchothy Davrajoo, et al., "Enhancing algebraic conceptual knowledge with aid of module using mastery learning approach", Procedia - Social and Behavioral Sciences, Vol. 8, 2010, pp. 362-369. https://doi.org/10.1016/j.sbspro.2010.12.051. 
pengetahuan konseptual yang perlu ditingkatkan.

\section{METODOLOGI PENELITIAN}

Penelitian ini menggunakan metode campuran dengan desain embeddedexperiment yaitu penelitian dengan pendekatan kuantitatif dan kualitatif yang dilakukan hampir bersamaan. ${ }^{20}$ Teknik pengambilan sampel dalam penelitian ini menggunakan stratified cluster random sampling atau sampel kelas acak. Langkah pengambilan sampel tersebut antara lain (1) membuat strata penduduk (tinggi, sedang, dan rendah) berdasarkan UN; (2) membuat kategori (tinggi, sedang, dan rendah) dari masing-masing 2-3 SD terpilih. Sampel yang digunakan dalam penelitian ini diambil dari tinggi, sedang, dan kategori sekolah rendah berdasarkan peringkat sekolah pada Ujian Nasional 2019. Data diperoleh dari Dinas Pendidikan Kota Surakarta. Variabel terikat dalam penelitian ini adalah penguasaan konsep, sedangkan variabel bebas dalam penelitian ini adalah media video. Populasi penelitian ini adalah seluruh siswa kelas IV SD Negeri di Kecamatan Laweyan Surakarta Tahun Pelajaran 2019/2020 yang berjumlah 868 siswa. Sampel dalam penelitian ini berjumlah 119 siswa kelas IV SD. Waktu penelitian dilakukan pada semester gasal tahun pelajaran 2019/2020.

Teknik analisis data dilakukan dengan menggunakan statistik deskriptif. Instrumen yang digunakan skala Likert dengan kategori skor 0, 1, 2, 3, dan 4. Data kuantitatif berupa angka untuk setiap pertanyaan kemudian dihitung sesuai dengan bentuk instrumen yang digunakan dengan validitas Aiken. Analisis kuantitatif dilakukan untuk mengetahui pengaruh pendekatan pembelajaran ICI dengan media video terhadap penguasaan konsep selalu hemat energi siswa. Hasil pre-test dan post-test sebagai data kuantitatif terlebih dahulu diuji normalitasnya menggunakan statistik SPSS versi 21. Uji normalitas penguasaan konsep menggunakan uji Kolmogorov-Smirnov dan uji homogenitas menggunakan Levene's Test. Jika hasil yang diperoleh normal dan homogen, maka uji bedanya menggunakan uji t sampel berpasangan. Data yang berdistribusi normal dan homogen memiliki nilai signifikansi data lebih besar dari 0,05 (Sig 0,05). Pengujian selanjutnya menggunakan effect size test untuk mengetahui seberapa jauh pengaruh pembelajaran terhadap variabel terikat. Besar kecilnya pengaruh strategi pembelajaran dihitung dengan menggunakan efek Cohen. Hasil perhitungan diinterpretasikan melalui

20 John W. Creswell, Research design: Qualitative, quantitative, and mixed method approaches,. (Thousand Oaks, CA: Sage Publication, 2009), pp. 1-26. 
deskripsi, ditunjukkan pada Tabel 1.

Tabel 1. Interpretasi Kekuatan Efek dengan r-skor

\begin{tabular}{|l|l|}
\hline \multicolumn{1}{|c|}{ Nilai r } & \multicolumn{1}{c|}{ Kriteria Kekuatan } \\
\hline$+/-0,8$ & sangat kuat \\
\hline$<+/-0,8$ & kuat \\
\hline$<+/-0,8$ & sedang \\
\hline$<+/-0,8$ & sederhana \\
\hline$<+/-0,8$ & lemah \\
\hline
\end{tabular}

Setelah diketahui nilai pre-test dan post-test, peningkatan penguasaan konsep siswa dianalisis menggunakan $\mathrm{N}$-gain untuk melihat perbedaan skor post-test dan pre-test setelah pembelajaran dilakukan. Interpretasi skor N-gain rata-rata ditunjukkan pada Tabel 2.

Tabel 2. Kriteria Peningkatan Skor N-Gain

\begin{tabular}{|l|l|}
\hline \multicolumn{1}{|c|}{ Keuntungan yang Dinormalisasi } & \multicolumn{1}{|c|}{ Kriteria Peningkatan } \\
\hline $\mathrm{G} 0,7$ & Tinggi \\
\hline $0,3 \mathrm{G}<0,7$ & Sedang \\
\hline $\mathrm{G}<0,3$ & Rendah \\
\hline
\end{tabular}

Selain itu juga terjadi peningkatan kategori penguasaan konsep dari pre-test menjadi post-test dengan menggunakan pedoman kategori penguasaan konsep Arikunto. ${ }^{21}$ Kategori penguasaan ditunjukkan pada Tabel 3.

Tabel 3. Kategori Penguasaan Konsep

\begin{tabular}{|l|l|}
\hline Nilai (\%) & \multicolumn{1}{|c|}{ Kategori } \\
\hline $0-45$ & Rendah \\
\hline $46-65$ & Sedang \\
\hline $66-85$ & Tinggi \\
\hline $86-100$ & Sangat tinggi \\
\hline
\end{tabular}

Selanjutnya dilakukan analisis masing-masing item untuk melihat indikator pencapaian materi selalu hemat energi. Aspek yang dianalisis adalah peningkatan penguasaan konsep masing-masing indikator dari pre-test dan post-test. Berdasarkan hasil analisis, peneliti melakukan analisis terhadap alasan siswa, keaktifan siswa, dan wawancara dengan beberapa data pendukung yang digunakan sebagai analisis kualitatif yang berfungsi untuk menjelaskan lebih dalam hasil analisis data kuantitatif. yang telah

\footnotetext{
${ }^{21}$ Suharsimi Arikunto, Prosedur penelitian suatu pendekatan praktek, (Jakarta: Rineka Cipta, 2013).
} 
diperoleh. Hal itu dilakukan untuk menggali pandangan siswa, kemudian dilakukan analisis berdasarkan sampel yang lebih luas.

\section{HASIL DAN PEMBAHASAN}

Hasil pre-test dan post-test penguasaan konsep oleh 119 siswa kelas IV SD Negeri di Kecamatan Laweyan, Surakarta, Indonesia, menunjukkan bahwa 119 siswa mengalami peningkatan nilai. Hasil uji normalitas diperoleh data pretest berdistribusi normal $(\alpha 0,05$ Sig $=0,194)$, dan data posttest berdistribusi normal $(\alpha 0,05 \mathrm{Sig}=0,106)$. Hasil uji homogenitas menunjukkan homogenitas data dengan $(\alpha 0,05 \mathrm{Sig}=0,585)$.

Pengujian selanjutnya adalah uji beda dengan menggunakan Paired Sample T-Test yang menghasilkan nilai sig $=0,000$. Kesimpulan yang diperoleh menunjukkan bahwa terdapat perbedaan skor penguasaan konsep pada materi selalu hemat energi antara sebelum dan sesudah intervensi. Langkah selanjutnya adalah menghitung ukuran efek melalui efek Cohen. Effect size dari hasil perhitungan adalah -0,834, dengan kategori sangat kuat. Hasil tersebut menunjukkan bahwa pendekatan pembelajaran Interactive Conceptual Instructions yang disertai dengan media video memiliki pengaruh yang kuat terhadap penguasaan konsep siswa pada materi selalu hemat energi. Peningkatan kategori penguasaan konsep dari pre-test ke post-test menghasilkan nilai N-Gain sebesar 1,02, dengan kategori rendah. Analisis selanjutnya adalah melihat peningkatan skor setiap indikator pertanyaan. Hasil analisis menunjukkan bahwa hampir semua indikator masalah mengalami peningkatan. Hasil keseluruhan skor untuk setiap indikator pertanyaan ditunjukkan pada Tabel 4. 
Tabel 4. Hasil Perbaikan untuk Setiap Indikator Soal

\begin{tabular}{|c|c|c|c|c|c|c|}
\hline \multirow[t]{2}{*}{ Pertanyaan } & \multirow{2}{*}{$\begin{array}{l}\text { Tingkat } \\
\text { Kognitif }\end{array}$} & \multirow[t]{2}{*}{ Konsep } & \multicolumn{2}{|c|}{$\begin{array}{c}\text { Persentase } \\
\text { Siswa Benar } \\
(\%)\end{array}$} & \multicolumn{2}{|c|}{$\begin{array}{c}\text { Tingkat } \\
\text { Penguasaan } \\
\text { Konsep } \\
\end{array}$} \\
\hline & & & $\begin{array}{c}\text { Pra- } \\
\text { tes }\end{array}$ & $\begin{array}{c}\text { Post- } \\
\text { test }\end{array}$ & Pra-tes & Post-test \\
\hline 1 & $\mathrm{C} 1$ & $\begin{array}{l}\text { Mengidentifikasi } \\
\text { sumber energi yang } \\
\text { berkaitan dengan } \\
\text { perannya bagi } \\
\text { kehidupan di bumi }\end{array}$ & 30 & 84 & Rendah & Tinggi \\
\hline 2 & $\mathrm{C} 4$ & $\begin{array}{l}\text { Menganalisis sumber } \\
\text { energi alternatif yang } \\
\text { dapat dimanfaatkan } \\
\text { dalam kehidupan } \\
\text { sehari-hari }\end{array}$ & 28 & 65 & Rendah & Sedang \\
\hline 3 & $\mathrm{C} 1$ & $\begin{array}{l}\text { Menyebutkan } \\
\text { gagasan utama yang } \\
\text { diperoleh dari teks } \\
\text { tertulis }\end{array}$ & 40 & 82 & Rendah & Tinggi \\
\hline 4 & $\mathrm{C} 1$ & $\begin{array}{l}\text { Menyebutkan ciri- } \\
\text { ciri sumber daya } \\
\text { alam berdasarkan } \\
\text { ciri-cirinya }\end{array}$ & 20 & 80 & Rendah & Tinggi \\
\hline 5 & $\mathrm{C} 2$ & $\begin{array}{l}\text { Sebutkan empat } \\
\text { contoh sumber daya } \\
\text { alam berdasarkan } \\
\text { ciri-cirinya }\end{array}$ & 16 & 66 & Rendah & Tinggi \\
\hline 6 & $\mathrm{C} 4$ & $\begin{array}{l}\text { Menghubungkan } \\
\text { karakteristik ruang } \\
\text { dengan sumber daya } \\
\text { alam di suatu } \\
\text { kabupaten }\end{array}$ & 40 & 65 & Rendah & Sedang \\
\hline 7 & $\mathrm{C} 4$ & $\begin{array}{l}\text { Menghubungkan } \\
\text { karakteristik ruang } \\
\text { dengan sumber daya } \\
\text { alam di suatu } \\
\text { kabupaten }\end{array}$ & 24 & 64 & Rendah & Sedang \\
\hline 8 & C6 & $\begin{array}{l}\text { Menciptakan respon } \\
\text { terkait kegiatan } \\
\text { ekonomi yang } \\
\text { memanfaatkan } \\
\text { sumber daya alam }\end{array}$ & 40 & 65 & Rendah & Sedang \\
\hline 9 & $\mathrm{C} 4$ & $\begin{array}{l}\text { Menganalisis gambar } \\
\text { terkait hak dan } \\
\text { kewajiban } \\
\text { masyarakat }\end{array}$ & 14 & 60 & Rendah & Sedang \\
\hline 10 & C6 & $\begin{array}{l}\text { Membuat poster } \\
\text { yang berisi tentang } \\
\text { hak dan kewajiban } \\
\text { mendapatkan listrik }\end{array}$ & 10 & 56 & Rendah & Sedang \\
\hline
\end{tabular}


Tingkat penguasaan konsep yang dimiliki siswa bergantung pada besarnya waktu yang dibutuhkan siswa untuk mempelajari konsep atau keterampilan dalam kondisi pembelajaran yang ideal. Jika kualitas pengajaran tinggi, siswa akan mudah memahami dan mungkin memerlukan sedikit waktu untuk belajar. Sebaliknya, jika kualitas pembelajaran rendah, siswa akan sulit memahami dan membutuhkan waktu lama untuk belajar. Indikator pencapaian konsep didasarkan pada taksonomi Bloom yang telah direvisi. $^{22}$

Penguasaan konsep siswa dalam menjawab pertanyaan sub materi tema selalu hemat energi menunjukkan bahwa siswa dapat mengidentifikasi sumber energi yang berkaitan dengan perannya bagi kehidupan di bumi. Pembelajaran ini diterapkan dengan pendekatan Interactive Conceptual Instructions dengan media video. Pendekatan pembelajaran interaktif konseptual memiliki empat karakteristik: fokus konseptual, interaksi kelas, bahan berbasis penelitian, dan penggunaan teks. ${ }^{23}$ Berdasarkan hasil penelitian yang telah dilakukan, pendekatan pembelajaran Interactive Conceptual Instructions dengan media video dapat membantu siswa meningkatkan penguasaan konsepnya. Siswa dengan tujuan penguasaan biasanya tertarik untuk belajar dengan tujuan itu saja.

Siswa tidak hanya mendengarkan presentasi, tetapi sekaligus meningkatkan keterampilannya melalui praktik, menganalisis, dan mengevaluasi pengetahuan yang telah diperolehnya. ${ }^{24}$ Penelitian lain mengungkapkan bahwa kegiatan belajar aktif dirancang dengan berfokus pada siswa, seperti: mengangkat tangan untuk berpartisipasi dalam mempelajari pengetahuan dan interaksi dengan teman untuk mendapatkan pengetahuan yang bermakna. ${ }^{25}$ Dengan demikian, perilaku dapat berubah dengan cepat, tepat, mudah, dan benar terkait kognitif, afektif, dan psikomotorik.

Pada tahap pertama fokus konseptual, siswa mengamati demonstrasi yang dilakukan oleh guru atau siswa sebagai bahan diskusi untuk siswa lain. Guru memberikan bimbingan dan perencanaan pembelajaran agar pencapaian materi dapat tersampaikan dengan maksimal. Tanpa kegiatan bimbingan dan penyelidikan, siswa menjadi dangkal sehingga

22 Lorin W. Anderson \& David R. Krathwohl, D.R. (Ed, Kerangka landasan untuk pembelajaran, pengajaran, dan asesmen, (Yogyakarta: Pustaka Pelajar, 2010).

${ }^{23}$ Rita Richey, The theoretical and conceptual bases of instructional design, (Unites States of America: Nichols Publishing Company, 1986).

${ }^{24}$ Kitti Vidermanova, \& Dusan Vallo, "Practical Geometry Tasks as a Method for Teaching Active Learning in Geometry", Procedia - Social and Behavioral Sciences, Vol. 191, 2015, pp. 1796-1800. https://doi.org/10.1016/j.sbspro.2015.04.421.

${ }^{25}$ Karen E. Levitt, "An analysis of elementary teachers' beliefs regarding the teaching and learning of science", Science Education, Vol. 86, No. 1, 2002, pp. 1-22. 
guru memfasilitasi pembelajaran dengan menggali prinsip-prinsip $\operatorname{dasar}^{26}$ atau mengembangkan pemahaman yang mendalam tentang pemahaman yang koheren. ${ }^{27}$ Bustillo dan Garaizer menekankan perlunya memberikan kesempatan kepada siswa untuk berkreasi karena mengubah konsep abstrak menjadi konkrit dan konsep yang dipahami dengan baik. ${ }^{28}$ Dinyatakan bahwa keterampilan yang membutuhkan pemikiran spasial seperti menggunakan bahan bentuk yang berbeda, membangun berbagai struktur dengan balok, dan menjangkau keseluruhan dengan menggabungkan bagian-bagian yang berbeda membentuk dasar penting dalam kesiapan sekolah. ${ }^{29}$

Pada interaksi kelas tahap kedua, siswa diberi kesempatan untuk mendiskusikan pemecahan masalah yang diberikan oleh guru melalui inkuiri. Kegiatan diskusi dapat meningkatkan keberhasilan praktisi, orientasi mengajar, dan belajar bagaimana merencanakan pelajaran berbasis inkuiri. Diskusi juga dapat meningkatkan pemahaman konseptual pada tingkat yang lebih tinggi.

Pada tahap ketiga, penggunaan bahan ajar berbasis penelitian berfungsi untuk meningkatkan penguasaan konsep siswa dan mengatasi kesulitan siswa dalam mempelajari konsep. Pada tahap ini, guru memberikan pertanyaan dan umpan balik secara lisan untuk memastikan tingkat pemahaman dan penguasaan konsep yang dimiliki siswa. Umpan balik bertujuan untuk merancang sistem informasi dan meningkatkan proses kesadaran selama proses pembelajaran. ${ }^{30}$ Umpan balik dapat dibangun berdasarkan profil pembelajaran dari fase proses regulasi, termasuk perencanaan, pemantauan, dan kegiatan sehingga memungkinkan untuk mendeteksi proses pembelajaran yang tidak efisien untuk beradaptasi. Umpan balik kognitif dapat mendukung pembelajaran regulasi pada tingkat tujuan khusus yang ditujukan untuk meningkatkan penguasaan konsep. Pada tahap keempat penggunaan teks, siswa melakukan kegiatan pendalaman materi dengan

${ }^{26}$ Gemma Corbalan, Liesbeth Kester, \& Jeroen JG Van Merriënboer, "Selecting learning tasks: Effects of adaptation and shared control on learning efficiency and task involvement", Contemporary Educational Psychology, Vol. 33, No. 4, 2018, pp. 733-756.

${ }^{27}$ M. Wang, Paul A. Kirschner, \& Susan M. Bridges, "Computer-based learning environments for deep learning in inquiry and problem-solving contexts", Proceedings of the 12th International Conference of the Learning Sciences (ICLS), 2016.

${ }^{28}$ Jon Bustillo \& Pablo Garaizar, "Using scratch to foster creativity behind bars: Two positive experiences in jail", Thinking Skills and Creativity, Vol. 19, 2016, pp. 60-72.

${ }^{29}$ Mehmet Toran, Ebru Aydin, \& Damla Etgiier, "Investigating the effects of STEM enriched implementations on school readiness and concept acquisition of children", Illkögretim Online, Vol. 19, No. 1, 2020, pp. 299-309. https://doi.org/10.17051/ilkonline.2020.656873.

${ }^{30}$ Gayane Sedrakyan, et al., "Linking learning behavior analytics and learning science concepts: Designing a learning analytics dashboard for feedback to support learning regulation", Computer in Human Behavior, Vol. 107, 2020, p. 105512. https://doi.org/10.1016/j.chb.2018.05.004. 
memperhatikan kembali rangkuman materi pembelajaran yang telah dilaksanakan dalam video pembelajaran. Kegiatan ini bertujuan untuk memperkuat daya ingat siswa tentang materi yang telah diperolehnya dalam pembelajaran.

Hasil analisis data menunjukkan bahwa terdapat perbedaan nilai pre-test dan nilai post-test penguasaan konsep siswa pada materi selalu hemat energi, dilihat dari nilai signifikansi Paired Sample T- Uji yang menghasilkan nilai sig $=0,000$ lebih kecil dari 0,005 . Perbedaan penguasaan konsep siswa sebelum dan sesudah diberikan perlakuan berupa penerapan pendekatan pembelajaran menunjukkan adanya pengaruh pembelajaran dengan pendekatan ICI terhadap penguasaan konsep siswa pada materi untuk selalu menghemat energi.

Hasil penelitian menunjukkan bahwa tingkat pengaruh pendekatan ICI dengan media video dalam meningkatkan penguasaan konsep siswa berada pada kategori sangat kuat. Nilai N-Gain dari hasil perhitungan menunjukkan bahwa peningkatan penguasaan konsep siswa berada pada kategori rendah. Hasil analisis setiap butir indikator menunjukkan bahwa siswa mengalami peningkatan tingkat penguasaan konsep dari rendah menjadi tinggi pada indikator mengingat $(\mathrm{C} 1)$ dan peningkatan tingkat penguasaan konsep dari rendah menjadi sedang pada indikator pemahaman (C2), analisis (C4), dan mencipta (C6).

Selain pendekatan pembelajaran, media pembelajaran juga dapat meningkatkan perhatian siswa terhadap pembelajaran. Borko et. menyimpulkan bahwa video bergerak lebih fokus dan memperdalam analisis, sehingga pembelajaran lebih menantang untuk berpikir dari waktu ke waktu. ${ }^{31}$ Media video juga menyediakan informasi yang mewakili situasi nyata dan memilih informasi yang mereka alami secara langsung. ${ }^{32}$

Pembelajaran dengan media video memiliki nilai visualisasi yang lebih tinggi dibandingkan dengan media gambar. Media video pembelajaran dapat mempersiapkan siswa untuk mengakses pengetahuan mereka, mengelola interaksi interpersonal mereka, dan meningkatkan potensi untuk membangun pengetahuan mereka. Penelitian yang dilakukan oleh Van Es et al. mengungkapkan bahwa penggunaan fasilitas mobile berbasis video dapat meningkatkan diskusi yang mempengaruhi penguasaan konsep siswa. ${ }^{33}$

Hasil ini sesuai dengan hipotesis yang dikemukakan peneliti bahwa penerapan

\footnotetext{
31 Hilda Borko, "Video as a tool for fostering productive discussions in mathematics professional development", Teaching and Teacher Education, Vol. 24, 2008, pp. 417 - 436.

${ }^{32}$ Georgene L. Troseth, "Is it life or is it Memorex? Video as a representation of reality", Developmental Review, Vol. 30, 2010, pp. 155-175. http://dx.doi.org/10.1016/j.dr.2010.03.007.

${ }^{33}$ Van Es et al., "A framework for the facilitation of teachers ' analysis of video", Journal of Teacher Education, Vol. 65, No. 4, 2014, pp. 340 - 356.
} 
pendekatan ICI pada media video memberikan lebih banyak waktu kepada siswa untuk merespon dan merefleksikan apa yang mereka baca atau amati, dan juga memberikan pandangan yang lebih sempit tentang interaksi kelas; dengan demikian, investigasi lebih terfokus pada pemikiran anak-anak. ${ }^{34}$ Salah satu kelebihan media video adalah siswa tidak hanya mendengar tetapi juga melihat. ${ }^{35}$

Hasil penelitian menunjukkan bahwa siswa mampu menyelesaikan masalah yang disajikan dalam bentuk pertanyaan konseptual dengan tingkat kognitif mulai dari tingkat mengingat (C1), memahami (C2), menganalisis (C4), dan mencipta (C6). Siswa dapat memecahkan masalah yang disajikan dalam bentuk pertanyaan konseptual dengan tingkat kognitif yang dimulai dari tingkat mengingat (C1), memahami (C2), menganalisis (C4), dan mencipta (C6). Instrumen penguasaan konsep yang digunakan termasuk materi selalu hemat energi. Pencapaian konsep pada indikator mengingat dan memahami meliputi materi sumber energi dan sumber daya alam. Menganalisis dan membuat indikator termasuk materi sumber daya alam dan membuat poster hemat energi.

Dalam pertanyaan no. 2 dengan tingkat analisis kognitif (C4), menyajikan masalah yang membahas sumber energi alternatif dengan memberikan tugas kepada siswa untuk menganalisis sumber energi alternatif dalam sebuah cerita pendek. Sebagian besar siswa merasa kesulitan untuk menyelesaikan masalah tersebut, dimana dalam mencari jawaban siswa masih bingung tentang manfaat yang dapat diperoleh untuk kehidupan sehari-hari. Dalam pertanyaan no. 6 dan 7 yang menyajikan permasalahan tentang sumber daya alam, sebagian besar siswa masih kesulitan menemukan jawaban yang tepat terkait hubungan antara karakteristik ruang/lokasi dengan sumber daya alam yang ada.

Pencapaian konsep indikator menciptakan (C6) meliputi kemampuan untuk menghasilkan sesuatu yang baru dengan mengorganisasikan beberapa elemen atau bagian menjadi suatu pola atau struktur yang tidak terlihat sebelumnya. ${ }^{36}$ Pada butir 8 disajikan pertanyaan-pertanyaan yang berkaitan dengan membuat tanggapan tentang kegiatan ekonomi yang memanfaatkan sumber daya alam beserta langkah-langkah atau upaya

\footnotetext{
${ }^{34}$ Alison Castro Superfine, Julie Amador, and John Bragelman. "Facilitating video-based discussions to support prospective teacher noticing", The Journal of Mathematical Behavior, Vol. 54, 2019, pp. 100681.

${ }_{35}$ Ghasem Barani, Omid Mazandarani, \& Seyyed Hassan Seyyed Rezaie "The effect of application of picture into picture audio- visual aids on vocabulary learning of young Iranian ELF learners", Procedia - Social and Behavioral Sciences, Vol. 2, No. 2, 2010, pp. 5362-5369. https://doi.org/10.1016/j.sbspro.2010.03.874.

${ }_{36}$ Lorin W. Anderson \& David R. Krathwohl, D.R. (Ed, Kerangka landasan untuk pembelajaran, pengajaran, dan asesmen, (Yogyakarta: Pustaka Pelajar, 2010).
} 
pelestariannya. Berdasarkan analisis jawaban siswa, kemampuan siswa dalam menulis tanggapan sudah cukup untuk dipahami. Namun, dalam menganalisis upaya yang harus dilakukan terkait dengan cerita, siswa menjawabnya bukan dalam konteks cerita. Misalnya, siswa menjawab "kegiatan penghijauan”. Sebaliknya, jawaban yang diharapkan terkait dengan upaya menjaga keseimbangan laut, seperti tidak menggunakan bahan peledak untuk menangkap ikan,

Butir nomor 10 tentang pembuatan poster yang berkaitan dengan penghematan energi. Pada indikator ini, siswa harus membuat poster sesuai topik dan kalimat yang digunakan menggunakan bahasa Indonesia baku. Berdasarkan analisis jawaban siswa, hanya sedikit siswa yang dapat menyelesaikan soal dengan jawaban yang tepat, dan tidak semua jawaban menggunakan kaidah penulisan yang benar. Dengan kata lain poster yang dibuat siswa tidak sesuai dengan masalah yang ditanyakan. Diantaranya masih ada siswa yang membuat poster yang tidak sesuai dengan topik yang diminta, kalimat yang digunakan tidak menggunakan kaidah penulisan yang benar, kurangnya kesinambungan antar kalimat, dan lain sebagainya.

Secara kuantitatif, penguasaan konsep siswa dapat ditelusuri dari perbandingan ratarata nilai pre-test dan post-test. Hasil analisis penguasaan konsep pada materi selalu hemat energi diperoleh nilai rata-rata post-test sebesar 80,19. Selain itu, jika dilihat dari nilai ratarata setiap pre-test dan post-test terlihat peningkatan nilai pre-test dan post-test siswa sebesar 23,32. Terbukti bahwa sebelum pembelajaran melalui pendekatan ICI dengan media video, nilai pretest hanya diperoleh nilai rata-rata 56,87.

Berdasarkan hasil wawancara terhadap sepuluh siswa, dapat disimpulkan bahwa soal yang dianggap sulit adalah tentang menganalisis manfaat sumber energi alternatif, hubungan antara karakteristik ruang/lokasi dengan sumber daya alam yang ada, membuat tanggapan terkait dengan ekonomi. kegiatan yang memanfaatkan sumber daya alam, dan membuat poster tentang penghematan energi. Siswa beranggapan bahwa materi tersebut sulit dipahami. Menurut sebagian siswa, kebiasaan siswa adalah menghafal materi tanpa memahami dan memperdalam konsep, sehingga siswa hanya mengikuti petunjuk guru secara terus menerus. Dengan demikian, dapat disimpulkan bahwa permasalahan terjadi karena penguasaan materi yang rendah. Hal itu bisa terjadi karena pembelajaran yang berpusat pada guru, penggunaan buku teks, dan kurangnya pendalaman materi.

Dari uraian hasil dan pembahasan di atas, dapat disimpulkan bahwa penerapan pendekatan ICI dengan media video menghasilkan nilai rata-rata yang lebih tinggi 
sehingga mempengaruhi penguasaan konsep siswa. Hal ini karena media video merangsang beberapa indera dan menjelaskan konsep abstrak dengan menggunakan kombinasi visual, teks, suara, dan musik, serta meningkatkan proses kognitif dan meningkatkan kinerja belajar siswa. Hasil analisis indikator penguasaan konsep masingmasing siswa untuk setiap butir indikator menunjukkan bahwa siswa kelas IV SD mengalami peningkatan tingkat penguasaan konsep dari rendah ke tinggi pada indikator daya ingat $(\mathrm{C} 1)$ dan peningkatan tingkat penguasaan konsep. dari rendah ke sedang pada indikator pemahaman (C2), analisis (C4), dan mencipta (C6). Hasil analisis masing-masing indikator dalam penguasaan konsep memiliki nilai rata-rata yang berbeda. Rata-rata setiap indikator diperoleh secara berurutan sesuai dengan tingkat tingkat kognitifnya, yaitu mengingat, memahami, menganalisis, dan mencipta. Indikator dengan tingkat penguasaan konsep kategori sulit adalah mencipta (C6), sedangkan indikator terendah adalah mengingat.

\section{KESIMPULAN}

Penelitian ini memiliki beberapa keterbatasan yaitu hanya menggunakan empat indikator dari enam indikator penguasaan konsep yang digunakan untuk mengukur kemampuan siswa tanpa dikaitkan dengan variabel pendukung lain yang terkait dengan pembelajaran, seperti aktivitas belajar, gaya belajar, dan lain-lain. pembelajaran yang biasa diterapkan di sekolah. Peneliti mempertimbangkan dengan mengkaji lebih lanjut pengukuran penguasaan konsep yang diterapkan dalam pendekatan pembelajaran interaktif dengan media pembelajaran. Guru diharapkan dapat meningkatkan penguasaan konsep siswa dengan merancang pembelajaran yang efektif agar proses pembelajaran terarah, dan mendukung aktivitas siswa dalam belajar untuk mencapai tujuan pembelajaran dengan pengajaran yang lebih berkualitas. Fasilitas penunjang pembelajaran diperlukan bagi guru untuk mengembangkan potensinya, seperti: mengikuti pelatihan inovasi pembelajaran. Setiap indikator penguasaan konsep sangat menarik jika dipadukan dengan pendekatan baru yang dapat menghasilkan efek positif bagi siswa, terutama sikapnya terhadap sekolah dan pembelajaran.

\section{DAFTAR PUSTAKA}

Anderson, W.L. \& Krathwohl, D.R. (Ed). (2010). Kerangka landasan untuk pembelajaran, pengajaran, dan asesmen. Yogyakarta: Pustaka Pelajar. 
Arikunto, S. (2013). Prosedur penelitian suatu pendekatan praktek. Jakarta: Rineka Cipta.

Arisanti, W. O. L., Sopandi, W., \& Widodo, A. (2016). Analisis penguasaan konsep dan keterampilan berpikir kreatif siswa SD melalui project based learning. EduHumaniora, 8(1), 82-95.

Barani, G., Mazandarani, O., \& Rezaie, S. H. S. (2010). The effect of application of picture into picture audio- visual aids on vocabulary learning of young Iranian ELF learners. Procedia - Social and Behavioral Sciences, 2(2), 5362-5369. https://doi.org/10.1016/j.sbspro.2010.03.874.

Borko, H., Jacobs, J., Eiteljorg, E., \& Pittman, M. (2008). Video as a tool for fostering productive discussions in mathematics professional development. Teaching and Teacher Education, 24, 417 - 436.

Bustillo, J., \& Garaizar, P. (2016). Using scratch to foster creativity behind bars: Two positive experiences in jail. Thinking Skills and Creativity, 19, 60-72.

Superfine, A. C., Amador, J., \& Bragelman, J. (2019). Facilitating video-based discussions to support prospective teacher noticing. The Journal of Mathematical Behavior, 54, 100681.

Changeiywo, J.M., Wambugu, P.W., Wachanga, S.W., 2011. Investigations of students' motivation toward learning secondary school physics through mastery learning approach. International Journal of Science and Mathematics Education, 9 (6), 1333-1350.

Corbalan, G., Kester, L., \& Van Merriënboer, J. J. (2008). Selecting learning tasks: Effects of adaptation and shared control on learning efficiency and task involvement. Contemporary Educational Psychology, 33(4), 733-756.

Creswell, J. W. (2009). Research design: Qualitative, quantitative, and mixed method approaches (Fourth Edi, pp. 1-26). Thousand Oaks, CA: Sage Publication.

Davrajoo, E., Tarmizi, R.A., Nawawi, M., \& Hassan, A. (2010). Enhancing algebraic conceptual knowledge with aid of module using mastery learning approach. Procedia - Social and Behavioral Sciences, 8, 362-369. https://doi.org/10.1016/j.sbspro.2010.12.051.

Erol, O., \& Kurt, A. A. (2017). The effects of teaching programming with Scratch on preservice information technology teachers' motivation and achievement. Computers in Human Behavior, 77, 11-18.

Estapa, A. T., \& Tank, K. M. (2017). Supporting integrated STEM in the elementary classroom: a professional development approach centered on an engineering design challenge. International Journal of STEM education, 4(1), 1-16.

Levitt, K.E. (2002). An analysis of elementary teachers' beliefs regarding the teaching and learning of science. Science Education, 86(1), 1-22.

Richey, R.C. (1986). The theoretical and conceptual bases of instructional design. Unites States of America: Nichols Publishing Company.

Samuelsson, R. (2018). Learning, culture and social interaction children's explorations of the concept of spinning in preschool: Science learning in mediated activity. Learning, Culture and Social Interaction, (January), 1-13. https://doi.org/10.1016/j.lcsi.2018.01.002. 
Savinainen, A., \& Scott, P. (2002). Using the force concept inventory to monitor student learning and to plan teaching. Physics Education, 37(1), 53-58. https://doi.org/10.1088/0031-9120/37/1/307.

Sedrakyan, G., Malmberg, J., Verbert, K., Järvelä, S., \& Kirschner, P. A. (2020). Linking learning behavior analytics and learning science concepts: Designing a learning analytics dashboard for feedback to support learning regulation. Computers in Human Behavior, 107, 105512. https://doi.org/10.1016/j.chb.2018.05.004.

Southerland, S.A., Gess-Newsome, J. \& Johnston, A. (2003). Portraying science in the classroom: The manifestation of scientists' beliefs in classroom practice. Journal of Research in Science Teaching, 40, 7,669-691.

Suryani, E., Ani, R., \& Wardono. (2016). Analisis pemahaman konsep IPA siswa SD menggunakan two-tier test melalui pembelajaran konflik kognitif. Jurnal Prima Edukasi.vol.5, issue 1, hlm 56-65.

Thibodeau-jarry, N., Bamira, D., \& Picard, M. (2018). Spotlight on special topics using simulation to teach transthoracic echocardiography to cardiology. Journal of the American College of Cardiology, 71(11), A2655. https://doi.org/10.1016/S07351097(18)33196-6.

Toran, M, Aydin, E \& Etgüer, D. (2020). Investigating the effects of STEM enriched implementations on school readiness and concept acquisition of children. Ilkögretim Online, 19(1), 299-309. https://doi.org/10.17051/ilkonline.2020.656873.

Troseth, G. L. (2010). Is it life or is it Memorex? Video as a representation of reality. Developmental Review, 30, 155-175. http://dx.doi.org/10.1016/j.dr.2010.03.007.

Tsai, C. Y. (2019). Improving students' understanding of basic programming concepts through visual programming language: The role of self-efficacy. Computers in Human Behavior, 95, 224-232. https://doi.org/10.1016/j.chb.2018.11.038.

Van Es, E., Tunney, J., Goldsmith, L., \& Seago, N. (2014). A framework for the facilitation of teachers ' analysis of video. Journal of Teacher Education, 65( 4), 340 $-356$.

Vidermanova, K., \& Vallo, D. (2015). Practical Geometry Tasks as a Method for Teaching Active Learning in Geometry. Procedia - Social and Behavioral Sciences, 191, 1796-1800. https://doi.org/10.1016/j.sbspro.2015.04.421.

Wang, M., Kirschner, P. A., \& Bridges, S. M. (2016). Computer-based learning environments for deep learning in inquiry and problem-solving contexts. In Proceedings of the 12th International Conference of the Learning Sciences (ICLS).

$\mathrm{Yu}$, S. F. K. (2017). How an integrative STEM curriculum can benefit students in engineering design practices. International Journal of Technology and Design Education, 27(1), 107-129. https://doi.org/10.1007/s10798-015-9328-x 